\title{
Presence of multiple abnormal immunologic markers is an independent prognostic factor of diffuse large B-cell lymphoma
}

\author{
Yiwen $\mathrm{Cao}^{1, *}$, Zhenhua $\mathrm{Liu}^{2, *}$, Wen $\mathrm{Wu}^{1, *}$, Ying Qian ${ }^{1, *}$, Qin $\mathrm{Shi}^{1}$, Rong Shen ${ }^{1}$, Binshen Ouyang ${ }^{3}$, Pengpeng $\mathrm{Xu}^{1}$, \\ Shu Cheng ${ }^{1}$, Jin $\mathrm{Ye}^{4}$, Yiming $\mathrm{Lu}^{4}$, Chaofu Wang ${ }^{3}$, Chengde Yang ${ }^{5}$, Li Wang $(\bowtie)^{1,4}$, Weili Zhao $(\bowtie)^{1,4}$ \\ ${ }^{1}$ State Key Laboratory of Medical Genomics, Shanghai Institute of Hematology, Ruijin Hospital Affiliated to Shanghai Jiao Tong University \\ School of Medicine, Shanghai 200025, China; ${ }^{2}$ Department of Ultrasonography, Ruijin Hospital Affiliated to Shanghai Jiao Tong University \\ School of Medicine, Shanghai 200025, China, ${ }^{3}$ Department of Pathology, Ruijin Hospital Affiliated to Shanghai Jiao Tong University School \\ of Medicine, Shanghai 200025, China, ${ }^{4}$ Pôle de Recherches Sino-Français en Science du Vivant et Génomique, Ruijin Hospital Affiliated to \\ Shanghai Jiao Tong University School of Medicine, Shanghai 200025, China; ${ }^{5}$ Department of Rheumatology, Ruijin Hospital Affiliated to \\ Shanghai Jiao Tong University School of Medicine, Shanghai 200025, China
}

(C) The Author(s) 2019. This article is published with open access at link.springer.com and journal.hep.com.cn

\begin{abstract}
Autoimmune diseases (ADs) increase the risk of non-Hodgkin's lymphoma and contribute to poor prognosis of patients. However, the association between immunologic markers and clinical outcome has rarely been investigated. This study aims to analyze the prognostic value of pretreatment immunologic markers in newly diagnosed patients with diffuse large B-cell lymphoma (DLBCL). We retrospectively reviewed the data on 502 patients with DLBCL treated in our institution from January 2013 to March 2018. Survival functions were estimated using Kaplan-Meier method and Cox regression model. The 3-year progression free survival (PFS) and overall survival (OS) rates were $\mathbf{7 0 . 2 \%}$ and $\mathbf{8 0 . 9 \%}$, respectively, and the complete remission (CR) rate was $78.1 \%$. Among the patients, those with multiple ( $\geqslant 3$ ) abnormal immunologic markers had significantly shorter 3-year PFS $(52.7 \%$ vs. $77.3 \%, P<0.001)$ and OS $(68.5 \%$ vs. $85.8 \%, P=0.001)$ than those without multiple abnormal immunologic markers. Multivariate analysis revealed that the presence of multiple abnormal immunologic markers and the elevated serum levels of lactate dehydrogenase were the independent adverse prognostic factors for PFS $(P=0.008, P<0.001)$ and OS $(P=0.003, P<0.001)$. Meanwhile, advanced Ann Arbor stage was an independent adverse prognostic factor for PFS $(P=0.001)$ and age $>60$ years for OS $(P=0.014)$. In conclusion, the immunologic status was closely related to lymphoma progression, and this study provides new insights into the risk stratification of patients with DLBCL.
\end{abstract}

Keywords immunologic marker; diffuse large B-cell lymphoma; prognosis

\section{Introduction}

Chronic immune stimulation and autoimmune disorders are risk factors for non-Hodgkin's lymphoma [1]. For example, systemic lupus erythematosus (SLE) and primary Sjögren syndrome (pSS) are associated with an increased risk of $\mathrm{B}$ cell lymphoma, especially marginal zone lymphoma. High activity of rheumatoid factor (RF) predisposes to diffuse large B cell lymphoma (DLBCL) $[1,2]$. RF, anti-double stranded DNA IgG (anti-dsDNA

Received August 10, 2018; accepted December 10, 2018

Correspondence: Li Wang, wl_wangdong@126.com;

Weili Zhao, zhao.weili@yahoo.com

${ }^{*}$ These authors equally contributed to this work.
$\mathrm{IgG}$ ), and anti-nuclear antibody (ANA) levels are substantially higher in patients with DLBCL than in nonDLBCL lymphoma patients [3]. Low C3 and C4 levels contribute to lymphoma development in pSS [4].

The correlation between abnormal immunologic status and clinical outcome in DLBCL remains unclear. In this study, we showed that the presence of multiple abnormal immunologic markers is significantly related to disease progression in newly diagnosed patients with DLBCL.

\section{Patients and methods}

Patients

From January 2013 to March 2018, 684 consecutive 
patients with de novo DLBCL (not otherwise specified, NOS) diagnosed based on registry data were enrolled in this study. Histological diagnosis was established according to World Health Organization (WHO) 2008 classification [5], with exclusion of mediastinal large B cell lymphoma $(n=66)$, primary central nervous system DLBCL $(n=62)$, and patients with DLBCL who received only supportive care $(n=54)$. Finally, 502 de novo patients with DLBCL were evaluated. The clinical features of the patients were described in Table 1.

Table 1 Clinical features of patients with DLBCL

\begin{tabular}{ll}
\hline Characteristic & Number (Percentage) \\
\hline All patients & $502(100.0 \%)$ \\
Gender & $273(54.4 \%)$ \\
Male & $229(45.6 \%)$ \\
female & \\
Age (year) & $232(46.2 \%)$ \\
$>60$ & $270(53.8 \%)$ \\
$\leqslant 60$ & $342(68.1 \%)$ \\
IPI score & $160(31.9 \%)$ \\
$0-2$ & \\
$3-5$ & $201(38.8 \%)$ \\
LDH & $301(61.2 \%)$ \\
Abnormal & \\
Normal & $443(88.2 \%)$ \\
Performance status (ECOG) & $59(11.8 \%)$ \\
$0-1$ & \\
$\geqslant 2$ & $347(69.1 \%)$ \\
No. of extranodal involvement & $155(30.9 \%)$ \\
$0-1$ & $283(56.4 \%)$ \\
$\geqslant 2$ & $219(43.6 \%)$ \\
Ann Arbor stage & \\
I-II & \\
III-IV &
\end{tabular}

IPI, international prognostic index; LDH, lactic dehydrogenase; ECOG, eastern cooperative oncology group.

Informed consent was obtained from all patients in accordance with the regulations of the Hospital and Institutional Review Boards and the Declaration of Helsinki.

\section{Immunologic marker detection}

Immunologic markers related to autoimmune diseases (ADs) and immunologic status were included. RF, antidsDNA IgG, and anti-Sjögren's-syndrome-related antigen (anti-SSA) are the representative markers in the diagnosis of rheumatoid arthritis (RA), SLE, and pSS, respectively [6-8]. ANA is commonly used in the diagnosis of ADs, including SLE and pSS [9], whereas antistreptolysin "O"
(ASO) is utilized in the diagnosis of rheumatic diseases [10]. Circulating immune complex (CIC) is a prominent feature of several autoimmune diseases, such as RA, SLE, and pSS [11], and decreased complements (C3 and C4) occur in the activate stage of ADs [12]. Serum immunoglobulins G, M, A, E (IgG, IgM, IgA, IgE) are elevated in various $\mathrm{ADs}$.

CIC, IgG, IgM, IgA, IgE, C3, C4, RF, anti-SSA, and ASO were assessed by turbidimetric inhibition immunoassay (Beckman Coulter, California, USA). Anti-dsDNA IgG and ANA were assessed by ELISA (Inova, California, USA). Serum immunologic markers were detected in patients with DLBCL at diagnosis.

\section{Treatment and response criteria}

All 502 patients received rituximab, cyclophosphamide, doxorubicin, vincristine, and prednisone-based (R-CHOP) chemotherapy. Treatment response was evaluated according to the WHO response criteria [13]. Complete remission (CR) is defined as no evidence of residual disease, partial response (PR) with at least a 50\% reduction in tumor burden from the onset of treatment. Progressive disease (PD) or relapse is defined as the appearance of any new lesion more than $1.5 \mathrm{~cm}$ at the end of therapy or at least a $50 \%$ increase in the longest diameter of any single or from nadir in the SPD of previously involved nodes. Stable disease (SD) is defined as the state of neither PR nor PD.

\section{Statistical analysis}

Baseline characteristics of patients were analyzed using two-sided $\chi^{2}$ test for categorical data. Logistic regression analysis was performed to analyze the risk factors of achieving CR. Progression-free survival (PFS) was calculated from the date when treatment began to the date when the disease progression was recognized or the date of the last follow-up. Overall survival (OS) time was measured from the date of diagnosis to the date of death or the last follow-up. Survival functions were estimated using the Kaplan-Meier method and compared by log-rank test. Univariate hazard estimates were generated with unadjusted Cox proportional hazards models. Covariates indicating significance on univariate analysis were included in the multivariate model. Statistical significance was defined as $P<0.05$. All statistical analyses were conducted using Statistical Package for the Social Sciences (SPSS) 22.0 software (SPSS Inc., Chicago, IL, USA).

\section{Results}

\section{Abnormal immunologic markers frequently occur in patients with DLBCL}

Among the 502 patients, $71.9 \%$ had abnormal 
immunologic markers. With regard to serum immunoglobulins and complements, elevated CIC, IgG, IgM, IgA and IgE levels were found in 147 (29.3\%), 76 (15.1\%), 21 (4.2\%), 20 (4.0\%), and 98 (19.5\%) patients, respectively.

Decreased levels of $\mathrm{C} 3$ and $\mathrm{C} 4$ were significantly associated with SLE [12], whereas their increased levels were observed in tumor or inflammatory cases [14]. Therefore, both changes in $\mathrm{C} 3$ and $\mathrm{C} 4$ were regarded as abnormal and found in 110 (21.9\%, high: 19, low: 91) and 95 (18.9\%, high: 13, low: 82) patients, respectively. Among the 377 patients with pretreatment results of serum RF, anti-dsDNA IgG, anti-SSA, ANA and ASO, 41 $(10.9 \%)$ had high serum RF, $3(0.8 \%)$ were positive for anti-dsDNA IgG, $6(1.6 \%)$ were positive for anti-SSA, 73 (19.4\%) had elevated ANA, and 18 (4.8\%) had elevated ASO level.

We further divided the patients into different groups according to the number of abnormal immunologic markers. Seventy-six patients (20.2\%) had multiple abnormal immunologic markers (i.e., $\geqslant 3$ abnormal immunologic markers). Among them, 11 patients had pre-diagnosed ADs, including RA (6 cases), SLE ( 2 cases), and pSS ( 3 cases). The medical history of the patients was recorded, and the diagnosis was thereafter confirmed according to the criteria [6-8].

These immunologic markers had relationship with the clinical features of the patients. IgM was increased in patients with multiple extranodal involvement $(P=0.008)$, and $\operatorname{IgE}$ was increased in patients with IPI scores $3-5(P=$ $0.034)$. $\mathrm{C} 3$ was abnormal in patients with poor ECOG $(P=$ $0.018), \mathrm{RF}$ was significantly increased in patients with IPI scores 3-5 $(P=0.012)$ and those with elevated LDH $(P=$ $0.029)$, anti-SSA was positive in patients with poor ECOG $(P=0.029)$, and ANA was increased in patients with poor ECOG $(P=0.044)$ (Table 2).

\section{Multiple abnormal immunologic markers do not affect treatment response in DLBCL}

Upon treatment, 392 patients $(78.1 \%)$ achieved CR. For 76 patients with multiple abnormal immunologic markers, their CR rate was $71.1 \%$. No significant difference in CR rate was observed in patients with and without multiple abnormal immunologic markers $(P=0.117)$. According to logistic regression, the factors statistically associated with lower CR rate were IPI scores 3-5 $(P<0.001)$, elevated LDH $(P<0.001)$, and advanced Ann Arbor stage $(P=$ 0.032 ) (Table 3).

\section{Multiple abnormal immunologic markers reflect poor clinical outcome in DLBCL}

The 3-year PFS and OS rates of the 502 patients with DLBCL were $70.2 \%$ and $80.9 \%$, respectively (Fig. 1A and 1B). After a median follow-up of 30 months, patients with multiple abnormal immunologic markers showed significantly inferior prognosis compared with those without multiple abnormal immunologic markers (control group). The 3-year PFS and OS rates of the two groups were $77.3 \%$ and $52.7 \%(P<0.001)$ and $85.8 \%$ and $68.5 \%(P=$ 0.001 ), respectively (Fig. 2A and $2 \mathrm{~B}$ ).

\section{Presence of multiple abnormal immunologic markers is an independent adverse prognostic factor in DLBCL}

Univariate analysis showed that the factors significantly associated with shorter PFS and OS were elevated LDH (both $P<0.001$ ), ECOG $\geqslant 2$ (both $P<0.001$ ), multiple extranodal involvement $(P=0.001$ and $P=0.015)$, advanced Ann Arbor stage (both $P<0.001$ ) and multiple abnormal immunologic markers (both $P=0.001$ ). The presence of age $>60$ years was of predictive value only for OS $(P<0.001)$ (Table 4).

The significant parameters in the univariate analysis were inputted into the Cox regression model for multivariate analysis. Elevated LDH $(P<0.001)$, advanced Ann Arbor stage $(P=0.001)$, and multiple abnormal immunologic markers $(P=0.008)$ predicted shorter PFS. However, age $>60$ years $(P=0.014)$, elevated LDH $(P<0.001)$, and multiple abnormal immunologic markers $(P=0.003)$ retained their independent prognostic effect on inferior OS (Table 5).

\section{Discussion}

DLBCL is a heterogeneous subtype of aggressive lymphoma. Approximately $30 \%-40 \%$ of the patients eventually relapse after receiving first-line chemotherapy $[15,16]$. Investigating the factors leading to poor clinical outcome is necessary to develop reasonable individualized treatment plans. In this study, we showed that the presence of multiple abnormal immunologic markers is related to resistance to conventional immunochemotherapy and is an independent unfavorable factor for PFS or OS in DLBCL.

Accumulating data revealed the association between specific $\mathrm{ADs}$ and the risk of non-Hodgkin lymphoma development [17]. However, the influence of immune disorders on the prognosis of the patients with DLBCL has seldom been studied. Here, we confirmed poor prognosis in patients with DLBCL who had multiple abnormal immunologic markers. Dysregulation of $\mathrm{T}$ regulatory, $\mathrm{T}$ helper, and B cells occurred in patients with lymphoma and ADs $[18,19]$. B cell proliferation and auto-antibody production are the features of RA, SLE, and pSS [2022]. Lymphomas may arise when the B cells evolve in an uncontrolled manner due to somatic hypermutation, which plays an important role in lymphomagenesis. BCL6 mutations are associated with a high frequency in 
Yiwen Cao et al.

97

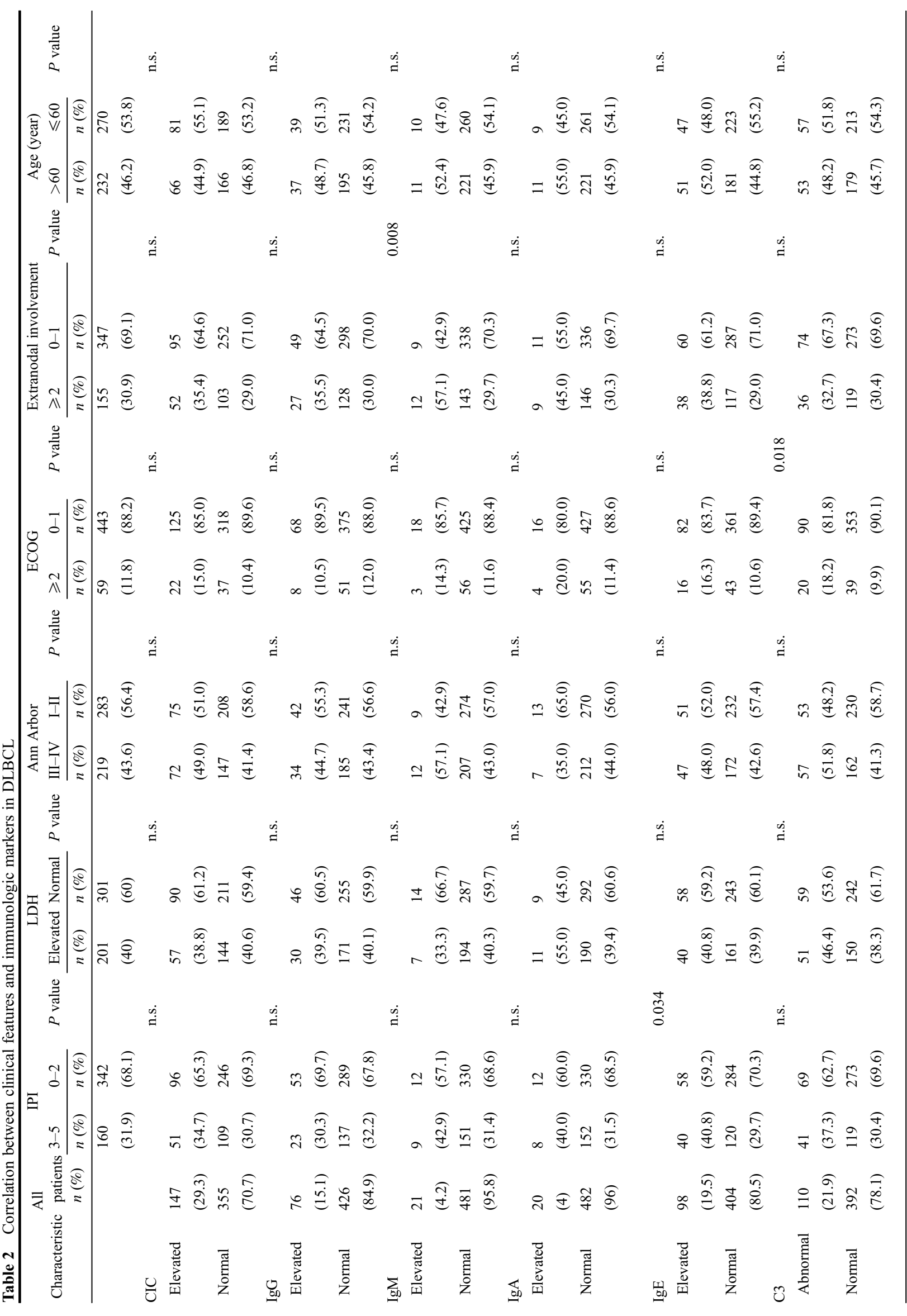


98

Multiple abnormal immunologic markers predict poor DLBCL

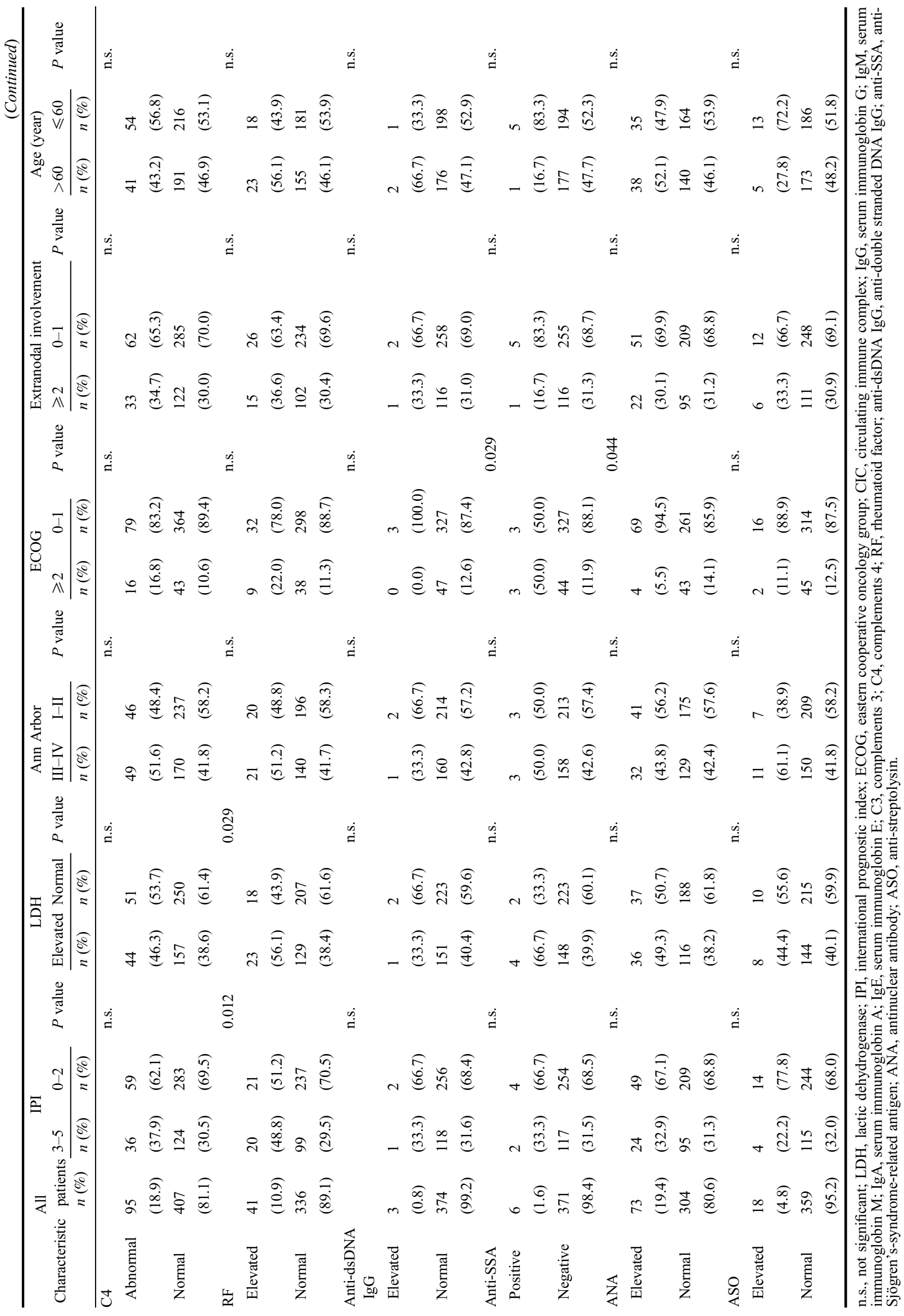


Table 3 Effects of clinical factors on treatment response

\begin{tabular}{|c|c|c|c|c|}
\hline Variates & Total & $\mathrm{CR}$ & non-CR & $P$ value \\
\hline Gender & & & & 0.708 \\
\hline Female & $229 / 502(45.6 \%)$ & $183 / 229(79.9 \%)$ & $46 / 229(20.1 \%)$ & \\
\hline Male & $273 / 502(54.4 \%)$ & $209 / 273(76.6 \%)$ & $64 / 273(23.4 \%)$ & \\
\hline Age (year) & & & & 0.768 \\
\hline$>60$ & $232 / 502(46.2 \%)$ & $177 / 232(76.3 \%)$ & $55 / 232(23.7 \%)$ & \\
\hline$\leqslant 60$ & $270 / 502(53.8 \%)$ & $215 / 270(79.6 \%)$ & $55 / 270(20.4 \%)$ & \\
\hline IPI scores & & & & $<0.001$ \\
\hline $3-5$ & $160 / 502(31.9 \%)$ & $102 / 160(63.8 \%)$ & $58 / 160(36.3 \%)$ & \\
\hline $0-2$ & $342 / 502(68.1 \%)$ & $290 / 342(84.8 \%)$ & $52 / 342(15.2 \%)$ & \\
\hline LDH & & & & $<0.001$ \\
\hline Elevated & $201 / 502(40.0 \%)$ & $131 / 201(65.2 \%)$ & $70 / 201(34.8 \%)$ & \\
\hline Normal & $301 / 502(60.0 \%)$ & $261 / 301(86.7 \%)$ & $40 / 301(13.3 \%)$ & \\
\hline ECOG & & & & 0.172 \\
\hline$\geqslant 2$ & $59 / 502(11.8 \%)$ & $32 / 59(54.2 \%)$ & $27 / 59(45.8 \%)$ & \\
\hline $0-1$ & $443 / 502(88.2 \%)$ & $360 / 443(81.3 \%)$ & $83 / 443(18.7 \%)$ & \\
\hline Extranodal & & & & 0.182 \\
\hline $0-1$ & $347 / 502(69.1 \%)$ & $281 / 347(81.0 \%)$ & $66 / 347(19.0 \%)$ & \\
\hline$\geqslant 2$ & $155 / 502(30.9 \%)$ & $111 / 155(71.6 \%)$ & $44 / 155(28.4 \%)$ & \\
\hline Ann Arbor stage & & & & 0.032 \\
\hline III-IV & $219 / 502(43.6 \%)$ & $147 / 219(67.1 \%)$ & $72 / 219(32.9 \%)$ & \\
\hline I-II & $283 / 502(56.4 \%)$ & $245 / 283(86.6 \%)$ & $38 / 283(13.4 \%)$ & \\
\hline $\mathrm{CIC}$ & & & & 0.575 \\
\hline Elevated & $147 / 502(29.3 \%)$ & $109 / 147(74.1 \%)$ & $38 / 147(25.9 \%)$ & \\
\hline Normal & $355 / 502(70.7 \%)$ & $283 / 355(79.7 \%)$ & $72 / 355(20.3 \%)$ & \\
\hline $\mathrm{IgG}$ & & & & 0.411 \\
\hline Elevated & $76 / 502(15.1 \%)$ & $59 / 76(77.6 \%)$ & $17 / 76(22.4 \%)$ & \\
\hline Normal & $426 / 502(84.9 \%)$ & $333 / 426(78.2 \%)$ & $93 / 426(21.8 \%)$ & \\
\hline $\operatorname{IgM}$ & & & & 0.089 \\
\hline Elevated & $21 / 502(4.2 \%)$ & $19 / 21(90.5 \%)$ & $2 / 21(9.5 \%)$ & \\
\hline Normal & $481 / 502(95.8 \%)$ & $373 / 481(77.5 \%)$ & $108 / 481(22.5 \%)$ & \\
\hline $\operatorname{IgA}$ & & & & 0.118 \\
\hline Elevated & $20 / 502(4.0 \%)$ & $13 / 20(65.0 \%)$ & $7 / 20(35.0 \%)$ & \\
\hline Normal & $482 / 502(96.0 \%)$ & $379 / 482(78.6 \%)$ & $103 / 482(21.4 \%)$ & \\
\hline $\operatorname{IgE}$ & & & & 0.093 \\
\hline Elevated & $98 / 502(19.5 \%)$ & $71 / 98(72.4 \%)$ & $27 / 98(27.6 \%)$ & \\
\hline Normal & $404 / 502(80.5 \%)$ & $321 / 404(79.5 \%)$ & $83 / 404(20.5 \%)$ & \\
\hline $\mathrm{C} 3$ & & & & 0.986 \\
\hline Abnormal & $110 / 502(21.9 \%)$ & $85 / 110(77.3 \%)$ & $25 / 110(22.7 \%)$ & \\
\hline Normal & $392 / 502(78.1 \%)$ & $307 / 392(78.3 \%)$ & $85 / 392(21.7 \%)$ & \\
\hline $\mathrm{C} 4$ & & & & 0.718 \\
\hline Abnormal & $95 / 502(18.9 \%)$ & $72 / 95(75.8 \%)$ & $23 / 95(24.2 \%)$ & \\
\hline Normal & $407 / 502(81.1 \%)$ & $320 / 407(78.6 \%)$ & $87 / 407(21.4 \%)$ & \\
\hline $\mathrm{RF}$ & & & & 0.221 \\
\hline Elevated & $41 / 377(10.9 \%)$ & $28 / 41(68.3 \%)$ & $13 / 41(31.7 \%)$ & \\
\hline Normal & $336 / 377(89.1 \%)$ & $271 / 336(80.7 \%)$ & $65 / 336(19.3 \%)$ & \\
\hline Anti-dsDNA IgG & & & & 0.374 \\
\hline Elevated & $3 / 377(0.8 \%)$ & $3 / 3(100.0 \%)$ & $0 / 3(0.0 \%)$ & \\
\hline Normal & $374 / 377(99.2 \%)$ & $296 / 374(79.1 \%)$ & $78 / 374(20.9 \%)$ & \\
\hline Anti-SSA & & & & 0.074 \\
\hline Positive & $6 / 377(1.6 \%)$ & $3 / 6(50.0 \%)$ & $3 / 6(50.0 \%)$ & \\
\hline Negative & $371 / 377(98.4 \%)$ & $296 / 371(79.8 \%)$ & $75 / 371(20.2 \%)$ & \\
\hline
\end{tabular}




\begin{tabular}{|c|c|c|c|c|}
\hline & & & & (Continued) \\
\hline Variates & Total & $\mathrm{CR}$ & non-CR & $P$ value \\
\hline ANA & & & & 0.351 \\
\hline Elevated & 73/377 (19.4\%) & $55 / 73(75.3 \%)$ & $18 / 73(24.7 \%)$ & \\
\hline Normal & $304 / 377(80.6 \%)$ & $244 / 304(80.3 \%)$ & $60 / 304(19.7 \%)$ & \\
\hline ASO & & & & 0.28 \\
\hline Elevated & $18 / 377(4.8 \%)$ & $12 / 18(66.7 \%)$ & $6 / 18(33.3 \%)$ & \\
\hline Normal & $359 / 377(95.2 \%)$ & $287 / 359(79.9 \%)$ & $72 / 359(20.1 \%)$ & \\
\hline Abnormal immunologic markers & & & & 0.117 \\
\hline$\geqslant 3$ & $76 / 377(20.2 \%)$ & $54 / 76(71.1 \%)$ & $22 / 76(28.9 \%)$ & \\
\hline $0-2$ & $301 / 377(79.8 \%)$ & $245 / 301(81.4 \%)$ & $56 / 301(18.6 \%)$ & \\
\hline
\end{tabular}

IPI, international prognostic index; LDH, lactic dehydrogenase; ECOG, eastern cooperative oncology group; CIC, circulating immune complex; IgG, serum immunoglobin G; IgM, serum immunoglobin M; IgA, serum immunoglobin A; IgE, serum immunoglobin E; C3, complements 3; C4, complements 4;

RF, rheumatoid factor; anti-dsDNA IgG, anti-double stranded DNA IgG; anti-SSA, anti-Sjögren's-syndrome-related antigen; ANA, antinuclear antibody; ASO, anti-streptolysin.
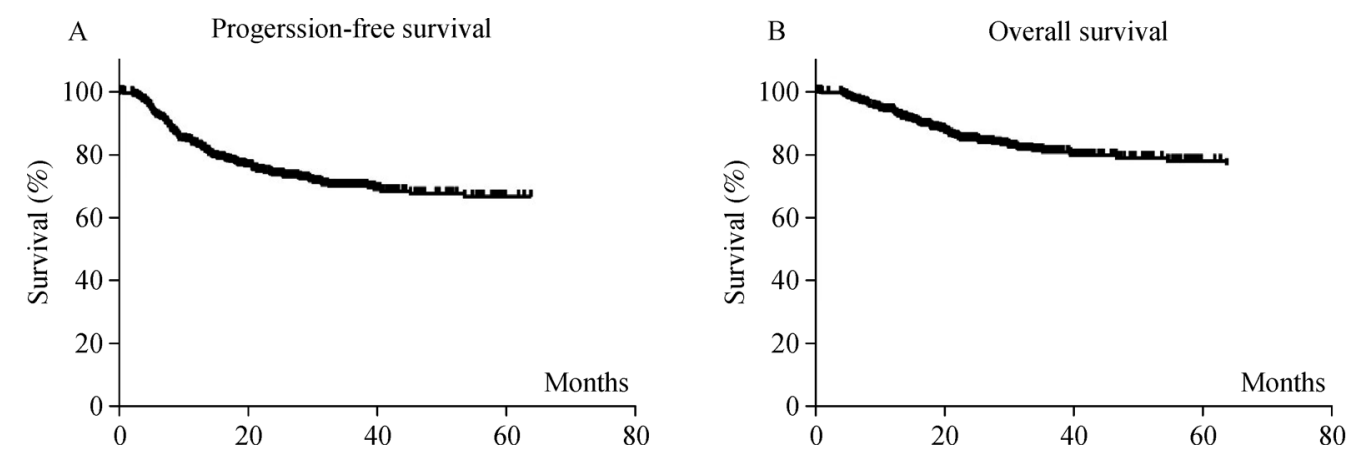

Fig. 1 Progression-free survival (A) and overall survival (B) curves of 502 patients with DLBCL.
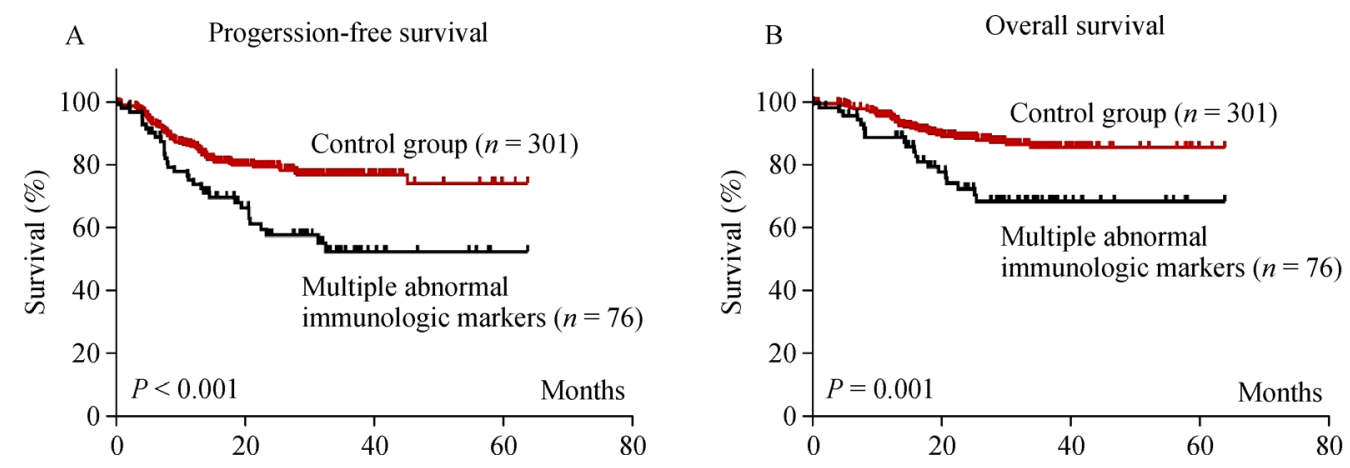

Fig. 2 Progression-free survival (A) and overall survival (B) curves of 377 patients with and without multiple abnormal immunologic markers.

DLBCL [23]. Another possible reason for the similar pathogenesis of immune disorder and lymphoma is their similar genetic backgrounds. Low expression of HLA Class I and II is related to decreased survival time of B cell lymphoma and determines the susceptibility to a range of ADs, such as RA, ulcerative colitis, and type I diabetes [24-27]. Hence, antigen-driven immune response is also relevant to the development of DLBCL. These results may explain the presence of multiple abnormal immunologic markers and their contribution to lymphoma progression in DLBCL.

Further investigation in multicenter studies should be conducted to confirm these findings. In conclusion, immunologic status is closely related to lymphoma progression, and this work provides new insights into the risk stratification of patients with DLBCL. 
Table 4 Univariate analysis on PFS and OS in patients with DLBCL

\begin{tabular}{|c|c|c|c|c|c|c|}
\hline \multirow{2}{*}{ Variates } & \multicolumn{3}{|c|}{ PFS } & \multicolumn{3}{|c|}{ OS } \\
\hline & HR & $95 \% \mathrm{CI}$ & $P$ value & HR & $95 \% \mathrm{CI}$ & $P$ value \\
\hline Age $>60$ years & I & / & 0.064 & 2.311 & $1.475-3.621$ & $<0.001$ \\
\hline Elevated LDH & 3.404 & $2.394-4.838$ & $<0.001$ & 3.756 & $2.361-5.976$ & $<0.001$ \\
\hline $\mathrm{ECOG} \geqslant 2$ & 3.116 & $2.096-4.633$ & $<0.001$ & 3.213 & $1.957-5.275$ & $<0.001$ \\
\hline Extranodal involvement $\geqslant 2$ & 1.775 & $1.263-2.494$ & 0.001 & 1.720 & $1.109-2.667$ & 0.015 \\
\hline Advanced stage & 3.551 & $2.468-5.109$ & $<0.001$ & 3.571 & $2.221-5.740$ & $<0.001$ \\
\hline Multiple abnormal Immunologic markers & 2.141 & $1.389-3.299$ & 0.001 & 2.511 & $1.441-4.377$ & 0.001 \\
\hline
\end{tabular}

LDH, lactate dehydrogenase; ECOG, eastern cooperative oncology group.

Table 5 Multivariate analysis on PFS and OS in patients with DLBCL

\begin{tabular}{|c|c|c|c|c|c|c|}
\hline \multirow{2}{*}{ Variable } & \multicolumn{3}{|c|}{ PFS } & \multicolumn{3}{|c|}{ OS } \\
\hline & $\overline{\mathrm{RR}}$ & $95 \% \mathrm{CI}$ & $P$ value & RR & HR $(95 \% \mathrm{CI})$ & $P$ value \\
\hline Age $>60$ years & / & / & 0.864 & 2.025 & $1.152-3.557$ & 0.014 \\
\hline Elevated LDH & 2.372 & $1.489-3.777$ & $<0.001$ & 3.649 & $2.025-6.574$ & $<0.001$ \\
\hline $\mathrm{ECOG} \geqslant 2$ & / & / & 0.165 & / & / & 0.135 \\
\hline Extranodal involvement $\geqslant 2$ & / & / & 0.132 & / & / & 0.319 \\
\hline Advanced stage & 2.285 & $1.413-3.696$ & 0.001 & / & l & 0.078 \\
\hline Multiple abnormal immunologic markers & 1.799 & $1.163-2.784$ & 0.008 & 2.326 & $1.333-4.059$ & 0.003 \\
\hline
\end{tabular}

LDH, lactate dehydrogenase; ECOG, eastern cooperative oncology group.

\section{Acknowledgements}

This study is supported, in part, by research funding from the National Natural Science Foundation of China (Nos. 81520108003, 81670716, and 81830007), Chang Jiang Scholars Program, the Shanghai Commission of Science and Technology (No. 16JC1405800), Shanghai Municipal Education Commission Gaofeng Clinical Medicine Grant Support (Nos. 20152206 and 20152208), Clinical Research Plan of SHDC (No. 16CR2017A), Multicenter Clinical Research Project by Shanghai Jiao Tong University School of Medicine (No. DLY201601), Collaborative Innovation Center of Systems Biomedicine and the Samuel Waxman Cancer Research Foundation.

\section{Compliance with ethics guidelines}

Yiwen Cao, Zhenhua Liu, Wen Wu, Ying Qian, Qin Shi, Rong Shen, Binshen Ouyang, Pengpeng Xu, Shu Cheng, Jin Ye, Yiming Lu, Chaofu Wang, Chengde Yang, Li Wang, and Weili Zhao declare no conflict of interest. All included procedures were conducted in accordance with the ethical standards of the responsible committee on human experimentation (institutional and national) and the Helsinki Declaration. Informed consent was obtained from all patients upon enrollment in the study.

Open Access This article is distributed under the terms of the Creative Commons Attribution 4.0 International License (http:// creativecommons.org/licenses/by/4.0/), which permits unrestricted use, distribution, and reproduction in any medium, provided the appropriate credit is given to the original author(s) and the source, and a link is provided to the Creative Commons license, indicating if changes were made.

\section{References}

1. Ekström Smedby K, Vajdic CM, Falster M, Engels EA, MartínezMaza O, Turner J, Hjalgrim H, Vineis P, Seniori Costantini A, Bracci PM, Holly EA, Willett E, Spinelli JJ, La Vecchia C, Zheng T, Becker N, De Sanjosé S, Chiu BC, Dal Maso L, Cocco P, Maynadié M, Foretova L, Staines A, Brennan P, Davis S, Severson R, Cerhan JR, Breen EC, Birmann B, Grulich AE, Cozen W. Autoimmune disorders and risk of non-Hodgkin lymphoma subtypes: a pooled analysis within the InterLymph Consortium. Blood 2008; 111(8): 4029-4038

2. Baecklund E, Iliadou A, Askling J, Ekbom A, Backlin C, Granath F, Catrina AI, Rosenquist R, Feltelius N, Sundström C, Klareskog L. Association of chronic inflammation, not its treatment, with increased lymphoma risk in rheumatoid arthritis. Arthritis Rheum 2006; 54(3): 692-701

3. Bilici A, Yapici HS, Ercan S, Seker M, Ustaalioglu BB, Salman T, Orcun A, Gumus M. The prevalence and significance of autoantibodies in patients with non-Hodgkin's lymphoma: are they correlated with clinicopathological features? J BUON 2012; 17: 502-507

4. Solans-Laqué RLópez-Hernandez A, Bosch-Gil JA, Palacios A, 
Campillo M, Vilardell-Tarres M. Risk, predictors, and clinical characteristics of lymphoma development in primary Sjögren's syndrome. Semin Arthritis Rheum 2011; 41(3): 415-423

5. Sabattini E, Bacci F, Sagramoso C, Pileri SA. WHO Classification of Tumours of Haematopoietic and Lymphoid Tissues. Pathologica 2010; 102(3): 83-87

6. Ramiro S, Gaujoux-Viala C, Nam JL, Smolen JS, Buch M, Gossec L, van der Heijde D, Winthrop K, Landewé R. Safety of synthetic and biological DMARDs: a systematic literature review informing the 2013 update of the EULAR recommendations for management of rheumatoid arthritis. Ann Rheum Dis 2014; 73(3): 529-535

7. Petri M, Orbai AM, Alarcón GS, Gordon C, Merrill JT, Fortin PR, Bruce IN, Isenberg D, Wallace DJ, Nived O, Sturfelt G, RamseyGoldman R, Bae SC, Hanly JG, Sánchez-Guerrero J, Clarke A, Aranow C, Manzi S, Urowitz M, Gladman D, Kalunian K,Costner M, Werth VP, Zoma A, Bernatsky S, Ruiz-Irastorza G, Khamashta MA, Jacobsen S, Buyon JP, Maddison P, Dooley MA, van Vollenhoven RF, Ginzler E, Stoll T, Peschken C, Jorizzo JL, Callen JP, Lim SS, Fessler BJ, Inanc M, Kamen DL, Rahman A, Steinsson K, Franks AG Jr, Sigler L, Hameed S, Fang H, Pham N, Brey R, Weisman MH, McGwin G Jr, Magder LS. Derivation and validation of the Systemic Lupus International Collaborating Clinics classification criteria for systemic lupus erythematosus. Arthritis Rheum 2012; 64(8): 2677-2686

8. Shiboski CH, Shiboski SC, Seror R, Criswell LA, Labetoulle M, Lietman TM, Rasmussen A, Scofield H, Vitali C, Bowman SJ, Mariette X; International Sjögren's Syndrome Criteria Working Group. 2016 American College of Rheumatology/European League Against Rheumatism Classification Criteria for Primary Sjögren's Syndrome: A Consensus and Data-Driven Methodology Involving Three International Patient Cohorts. Arthritis Rheumatol 2017; 69 (1): $35-45$

9. Horvath IF, Szodoray P, Zeher M. Primary Sjögren's syndrome in men: clinical and immunological characteristic based on a large cohort of Hungarian patients. Clin Rheumatol 2008; 27(12): 14791483

10. Watanabe N, Arimura A, Kobayashi M, Oshima M. ASO, ASK and ADNase-B values rheumatic fever, rheumatic heart disease and other infections by hemolytic streptococcus: Proceedings of the IV Conference on Prevention for Rheumatic Fever and Rheumatic Heart Disease, January 1979, Kyoto. Jpn Circ J 1980; 44(10): 808809

11. Ohyama K, Baba M, Tamai M, Aibara N, Ichinose K, Kishikawa N, Kawakami A, Kuroda N. Proteomic profiling of antigens in circulating immune complexes associated with each of seven autoimmune diseases. Clin Biochem 2015; 48(3): 181-185

12. Tsukamoto H, Ueda A, Nagasawa K, Tada Y, Niho Y. Increased production of the third component of complement (C3) by monocytes from patients with systemic lupus erythematosus. Clin Exp Immunol 1990; 82(2): 257-261

13. Cheson BD, Pfistner B, Juweid ME, Gascoyne RD, Specht L, Horning SJ, Coiffier B, Fisher RI, Hagenbeek A, Zucca E, Rosen ST, Stroobants S, Lister TA, Hoppe RT, Dreyling M, Tobinai K, Vose JM, Connors JM, Federico M, Diehl V; International Harmonization Project on Lymphoma. Revised response criteria for malignant lymphoma. J Clin Oncol 2007; 25(5): 579-586

14. Candido J, Hagemann T. Cancer-related inflammation. J Clin
Immunol 2013; 33( Suppl 1): S79-S84

15. Vitolo U, Chiappella A, Angelucci E, Rossi G, Liberati AM, Cabras MG, Botto B, Ciccone G, Gaidano G, Falchi L, Freilone R, Novero D, Orsucci L, Pavone V, Pogliani E, Rota-Scalabrini D, Salvi F, Tonso A, Tucci A, Levis A; Gruppo Italiano Multiregionale e Leucemie (GIMURELL). Dose-dense and high-dose chemotherapy plus rituximab with autologous stem cell transplantation for primary treatment of diffuse large B-cell lymphoma with a poor prognosis: a phase II multicenter study. Haematologica 2009; 94(9): 12501258

16. Sayegh ET, Bloch O, Parsa AT. Complement anaphylatoxins as immune regulators in cancer. Cancer Med 2014; 3(4): 747-758

17. Fallah M, Liu X, Ji J, Försti A, Sundquist K, Hemminki K. Autoimmune diseases associated with non-Hodgkin lymphoma: a nationwide cohort study. Ann Oncol 2014; 25(10): 2025-2030

18. Ngalamika O, Zhang Y, Yin H, Zhao M, Gershwin ME, Lu Q. Epigenetics, autoimmunity and hematologic malignancies: a comprehensive review. J Autoimmun 2012; 39(4): 451-465

19. Hayter SM, Cook MC. Updated assessment of the prevalence, spectrum and case definition of autoimmune disease. Autoimmun Rev 2012; 11(10): 754-765

20. Firestein GS. Evolving concepts of rheumatoid arthritis. Nature 2003; 423(6937): 356-361

21. Bernatsky S, Clarke A, Ramsey-Goldman R. Malignancy and systemic lupus erythematosus. Curr Rheumatol Rep 2002; 4(4): 351-358

22. Fox RI, Kang HI. Pathogenesis of Sjogren's syndrome. Rheum Dis Clin North Am 1992; 18(3): 517-538

23. Nogai H, Dörken B, Lenz G. Pathogenesis of non-Hodgkin's lymphoma. J Clin Oncol 2011; 29(14): 1803-1811

24. Riemersma SA, Jordanova ES, Schop RF, Philippo K, Looijenga LH, Schuuring E, Kluin PM. Extensive genetic alterations of the HLA region, including homozygous deletions of HLA class II genes in B-cell lymphomas arising in immune-privileged sites. Blood 2000; 96(10): 3569-3577

25. Lech-Maranda E, Bienvenu J, Michallet AS, Houot R, Robak T, Coiffier B, Salles G. Elevated IL-10 plasma levels correlate with poor prognosis in diffuse large B-cell lymphoma. Eur Cytokine Netw 2006; 17(1): 60-66

26. Rimsza LM, Roberts RA, Miller TP, Unger JM, LeBlanc M, Braziel RM, Weisenberger DD, Chan WC, Muller-Hermelink HK, Jaffe ES, Gascoyne RD, Campo E, Fuchs DA, Spier CM, Fisher RI, Delabie J, Rosenwald A, Staudt LM, Grogan TM. Loss of MHC class II gene and protein expression in diffuse large B-cell lymphoma is related to decreased tumor immunosurveillance and poor patient survival regardless of other prognostic factors: a follow-up study from the Leukemia and Lymphoma Molecular Profiling Project. Blood 2004; 103(11): 4251-4258

27. Urayama KY, Jarrett RF, Hjalgrim H, Diepstra A, Kamatani Y, Chabrier A, Gaborieau V, Boland A, Nieters A, Becker N, Foretova L, Benavente Y, Maynadié M, Staines A, Shield L, Lake A, Montgomery D, Taylor M, Smedby KE, Amini RM, Adami HO, Glimelius B, Feenstra B, Nolte IM, Visser L, van Imhoff GW, Lightfoot T, Cocco P, Kiemeney L, Vermeulen SH, Holcatova I, Vatten L, Macfarlane GJ, Thomson P, Conway DI, Benhamou S, Agudo A, Healy CM, Overvad K, Tjønneland A, Melin B, Canzian F, Khaw KT, Travis RC, Peeters PH, González CA, Quirós JR, 
Sánchez MJ, Huerta JM, Ardanaz E, Dorronsoro M, ClavelChapelon F, Bueno-de-Mesquita HB, Riboli E, Roman E, Boffetta P, de Sanjosé S, Zelenika D, Melbye M, van den Berg A, Lathrop M,
Brennan P, McKay JD. Genome-wide association study of classical Hodgkin lymphoma and Epstein-Barr virus status-defined subgroups. J Natl Cancer Inst 2012; 104(3): 240-253 